\title{
The Link Between Local Recurrence and Distant Metastases in Patients With Rectal Cancer
}

\author{
THEODOR JUNGINGER ${ }^{1}$, URSULA GOENNER ${ }^{1}$, TONG T.TRINH ${ }^{2}$, ACHIM HEINTZ ${ }^{3}$, \\ ANDRÉ LOLLERT $^{4}$, MARIA BLETTNER ${ }^{5}$ and DANIEL WOLLSCHLAEGER ${ }^{5}$ \\ ${ }^{1}$ Department of General and Abdominal Surgery at the University Medical \\ Centre of the Johannes Gutenberg-University, Mainz, Germany; \\ ${ }^{2}$ Department of Heart, Chest and Vascular Surgery at the University Medical \\ Centre of the Johannes Gutenberg-University, Mainz, Germany; \\ ${ }^{3}$ Department of General, Visceral and Vascular Surgery at the Catholic Hospital Mainz, Mainz, Germany; \\ ${ }^{4}$ Department of Diagnostic and Interventional Radiology at the University \\ Medical Centre of the Johannes Gutenberg-University, Mainz, Germany; \\ ${ }^{5}$ Institute of Medical Biostatistics, Epidemiology and Informatics at the University \\ Medical Centre of the Johannes Gutenberg-University, Mainz, Germany
}

\begin{abstract}
Background/Aim: The relationships between local recurrence (LR), the development of distant metastases (DM) and prognosis in patients with rectal cancer remain unclear. Patients and Methods: In 606 patients who underwent curative resection, the role of $L R$ was assessed retrospectively by timedependent multivariate Cox models with inverse probability of treatment weighting taking into account competing risks. Results: Patients with LR had more DM than patients without LR (49/79, 62\% vs. 86/524, 16.4\%; p<0.001); $37 \%$ of LRassociated DM developed before or at LR, 63\% after diagnosis of LR. Fifty-five percent of patients without DM at diagnosis of LR later developed DM. In these patients, the incidence of $D M$ significantly exceeded the incidence in patients without LR. DM risk was most strongly associated with preceding $L R$ and stage UICC III and II. Conclusion: There is a causal link between $L R$ and DM in patients with rectal cancer.
\end{abstract}

Total mesorectal excision (TME) significantly reduces the incidence of local recurrence (LR) in patients with rectal cancer, and pre-operative or postoperative radiotherapy (RT) or chemoradiotherapy (CRT) can further reduce the risk of LR (1-3). However, evidence of the influence of LR

Correspondence to: D. Wollschlaeger, Institute of Medical Biostatistics, Epidemiology and Informatics at the Medical Centre of the Johannes Gutenberg-University, Langenbeckstraße 1, D 55131 Mainz, Germany. Tel: +49 06131177029, Fax: +49 06131172968, e-mail: Wollschlaeger@uni-mainz.de

Key Words: Rectal cancer, local recurrence, distant metastases, oncological outcome. reduction on distant metastases (DM) and overall survival (OS) remains inconclusive. Though some non-randomized studies have demonstrated a correlation between LR reduction and improved survival after TME (4-6), reduced LR did not change the incidence of DM (7-9) or improve survival in other studies (1-3).

The underlying question is whether rectal cancer is potentially already a systemic disease at diagnosis, with both LR and DM being independent consequences of advanced and aggressive cancer. Alternatively, LR itself may be the origin of DM. This view is consistent with the higher incidence of DM in patients with LR compared to patients without $\operatorname{LR}(6,10,11)$, the reduction of DM combined with LR in randomized studies in which RT reduced LR (12), and observations of an association between DM and LR in cancers in other organs (13-16).

The conflicting results may be due to methodological issues. LR and DM must be treated as time-dependent variables in survival analyses to avoid immortal time bias (17). In addition, LR and DM probably interact in their effect on cancer-specific survival (CSS) and OS. Studies describing only the incidence of DM with or without LR are unable to assess the causal role of LR in DM, as they fail to distinguish between LR followed by DM and DM occurring simultaneously with or prior to LR. If the time course of LR and DM is not taken into account, an elevated incidence of DM in patients with LR may partially be a result of immortal time bias. Patients with LR must have survived until LR diagnosis and, therefore, potentially had more time to develop DM than patients without LR.

Therefore, the long-term results of patients with rectal cancer with and without TME were analyzed in the present 
study to determine the impact of reduced LR after TME on the incidence of DM and OS. This study also shows how the analysis of patients with LR followed by DM compared to patients with DM before or at LR sheds light on whether LR is the source of systemic disease besides the primary cancer.

\section{Patients and Methods}

Patient data. A total of 1032 consecutive patients with histologically proven rectal adenocarcinoma underwent surgery at the Department of General and Abdominal Surgery at the University Medical Centre Mainz (Germany) from 1985 to 2007. All cancers with a distal margin $\leq 16 \mathrm{~cm}$ from the anal verge were classified as rectal according to UICC classification (18). Patient data were collected prospectively using a standardized form. Anterior resection (AR; >6 $\mathrm{cm}$ above the anal verge), low anterior resection (LAR; anastomosis $\leq 6 \mathrm{~cm}$ from the anal verge), abdominoperineal extirpation (APE), and Hartmann procedures were performed. After introduction of TME with preservation of the autonomic nerves (19) in 1996, neoadjuvant CRT was preferred for patients with an involved mesorectal fascia on pre-therapeutic pelvic magnetic resonance imaging (MRI).

Patients had regular follow-up visits according to a standardized program until the fifth postoperative year following hospital discharge. The number of visits (after 6, 12, 18, and 24 months and yearly thereafter) and imaging procedures did not change during the observation period, except computed tomography (CT) of the chest replaced thoracic X-ray in 1990. The patients' status was updated in 2011 and 2012, including vital status, presence/absence of disease, results of follow-up visits, date and treatment of tumor recurrence, and the date and cause of death if applicable, by contacting the patients and their families, treating physicians, and hospitals. Follow-up ended at date of death or on December 31, 2012, whichever occurred first.

Definitions. Local control was determined by using the time from surgery to confirmed LR, which was defined as clinical, radiological, or histological evidence of a recurrent tumor in the anastomosis, pelvis, or perineum, regardless of DM. DM were defined by radiological evidence of tumor spread, with or without LR. In patients with LR and DM, DM were classified as being present before or simultaneously with LR diagnosis, as opposed to following the diagnosis of LR. OS was defined as the time to death by any cause. CSS was defined as the time to death due to rectal cancer, i.e., tumor recurrence at time of death or death after surgery. Patients who died from other causes were censored at time of death.

Exclusion criteria. Patients with concomitant DM, non-curative resection ( $R 1$ and R2), or emergency surgery $(n=265)$ were excluded from the study. As preoperative RT may underestimate tumor stage (20) and chemotherapy may influence the incidence of DM, patients that had undergone adjuvant chemotherapy $(n=41)$, adjuvant CRT $(n=79)$, and preoperative CRT $(n=41)$ were investigated separately. To ensure a homogenous collective, 606 patients with $\mathrm{R} 0$ resection were enrolled in the analysis.

Statistical analysis. Univariate analysis of OS and CSS was carried out using Kaplan-Meier curves and log-rank tests for group differences. Multivariate Cox regression was used to assess OS and
CSS with age at surgery, TME, UICC stage, and grading (G1/G2 vs. G3/G4) as baseline covariates. LR and DM were time-varying covariates. The interaction between LR and DM allowed for a differential effect of LR depending on DM status.

The theoretical association of LR with DM was assessed using multivariate Cox regression for the cause-specific hazard of DM, with patients censored at the time of death using age at surgery, TME, UICC stage, and grading (G1/G2 vs. G3/G4) as baseline covariates and LR as a time-varying covariate. Inverse probability of treatment weighting (IPTW) (21) in Cox regression accounted for possible confounding factors associated with TME. The propensity for TME was estimated using logistic regression with sex, ASA status, UICC stage, pT1/pT2 vs. pT3/pT4 stage, nodal status, and grading as covariates (doubly robust approach) (22). Cox regression used a robust sandwich estimator for the variance (23). To assess the proportional hazards assumption in Cox regression models, the correlation between scaled Schoenfeld residuals and log time was examined. The cumulative incidence of LR alone, DM, and death was estimated from a multi-state model taking into account competing risks (24). The model was implemented in the $\mathrm{R}$ environment for statistical computing version 3.5.2 (25) with package etm (empirical transition matrix) (26) which provides the Aalen-Johansen estimator.

$p$-Values were unadjusted for multiple comparisons and considered significant if $<0.05$. A baseline data analysis was carried out in SPSS Statistics (version 23.0, IBM, Ehningen, Germany). The survival analysis was carried out using the $\mathrm{R}$ with packages survival (27).

Ethics. All patients provided informed consent for data collection and evaluation. All procedures involving human participants were performed in accordance with the ethical standards of the institutional and/or national ethical committees, as well as the 1984 Helsinki declaration and its later amendments or comparable ethical standards.

\section{Results}

Patient characteristics are summarized in Table I. TME was performed in 263 (43.4\%) patients, and 343 patients (56.6\%) underwent curative resection without TME.

Local recurrence and distant metastases. LR with or without DM was observed in 79 patients (13.0\%; Table II). Forty-two patients had symptoms of LR and 37 were asymptomatic. LR was diagnosed by rectoscopy $(\mathrm{n}=27), \mathrm{CT}$ $(n=46)$, or MRI $(n=6)$. Patients who underwent TME had a significantly lower rate of LR $(7.6 \%)$ than patients who did not undergo TME (17.2\%, $p<0.001$, Table II). The median time to LR was 14 months (range $=3-91$ months) in patients without and 17 months (range $=6-85$ months) in patients with TME. The median survival after LR was 12 months and 18 months for patients who underwent and patients who did not undergo TME, respectively $(p=0.529)$. In univariate analysis, tumor stage, tumor grading, TME, and APE were significantly associated with LR (Table II). In IPTW-weighted Cox regression, the most important independent prognostic factors for risk of LR were 
Table I. Patient characteristics with and without TME.

\begin{tabular}{|c|c|c|c|c|}
\hline & $\begin{array}{c}\text { Total } \\
\mathrm{n}=606\end{array}$ & $\begin{array}{c}\text { Without } \\
\text { TME (\%) } \\
\text { n=343 }\end{array}$ & $\begin{array}{c}\text { With } \\
\text { TME }(\%) \\
\text { n=263 }\end{array}$ & $p$-Value \\
\hline Age (median) & 67 years & 66 years & 68 years & 0.075 \\
\hline Follow-up (median) & 72 months & 82 months & 66 months & $<0.001$ \\
\hline Gender & & & & 0.03 \\
\hline Female & 240 & $149(43)$ & $91(34)$ & \\
\hline Male & 366 & $194(56)$ & $172(65)$ & \\
\hline ASA classification* & & & & 0.003 \\
\hline $\mathrm{I} / \mathrm{II}$ & 254 & $123(36)$ & $131(50)$ & \\
\hline III & 291 & $183(54)$ & $108(41)$ & \\
\hline IV & 58 & $34(10)$ & $24(9)$ & \\
\hline Localization & & & & $<0.001$ \\
\hline Upper third & 144 & $67(20)$ & $77(30)$ & \\
\hline Middle third & 256 & $138(40)$ & $118(45)$ & \\
\hline Lower third & 206 & $138(40)$ & $68(26)$ & \\
\hline Type of operation & & & & $<0.001$ \\
\hline $\mathrm{AR}$ & 98 & $42(12)$ & $56(21)$ & \\
\hline LAR & 315 & $150(44)$ & $165(63)$ & \\
\hline APE & 182 & $145(42)$ & $37(14)$ & \\
\hline Hartmann & 11 & $6(2)$ & $5(2)$ & \\
\hline $\mathrm{T}$ stage & & & & 0.73 \\
\hline 1 & 78 & $43(13)$ & $35(13)$ & \\
\hline 2 & 232 & $126(37)$ & $106(40)$ & \\
\hline 3 & 272 & $159(46)$ & $113(43)$ & \\
\hline 4 & 24 & $15(4)$ & $9(3)$ & \\
\hline $\mathrm{N}$ stage & & & & 0.010 \\
\hline 0 & 462 & $246(72)$ & $216(82)$ & \\
\hline 1 & 103 & $70(20)$ & $33(13)$ & \\
\hline 2 & 41 & $27(8)$ & $14(5)$ & \\
\hline Grading** & & & & 0.18 \\
\hline $\mathrm{G} 1 / 2$ & 498 & $279(88)$ & $219(84)$ & \\
\hline $\mathrm{G} 3 / 4$ & 82 & $39(12)$ & $43(16)$ & \\
\hline UICC stage & & & & 0.008 \\
\hline I & 266 & $135(40)$ & $130(49)$ & \\
\hline II & 197 & $111(32)$ & $86(33)$ & \\
\hline III & 143 & $96(28)$ & $47(18)$ & \\
\hline Local recurrence & & & & $<0.001$ \\
\hline No & 527 & $284(83)$ & $243(92)$ & \\
\hline Yes & 79 & $59(17)$ & $20(8)$ & \\
\hline Distant metastases* & & & & 0.014 \\
\hline No & 468 & $251(74)$ & $217(81)$ & \\
\hline Yes & 135 & $89(26)$ & $46(19)$ & \\
\hline
\end{tabular}

Percentages may add up to more than $100 \%$ due to rounding. *Data missing in 3 cases; **data missing in 26 cases (4\%). ASA: Risk classification of American Society of Anesthesiologists.

preceding DM, followed by tumor stage III and II, APE, and tumor grading, whereas TME was not a significant protective factor (Table III).

DM were observed in $135 / 603$ patients (22.3\%; Table IV). DM were diagnosed by $\mathrm{CT}$ in 85 patients, by abdominal sonography in 38 patients, by $x$-ray of the chest in 5 patients, and by other methods in 7 patients. Patients who underwent TME had fewer DM associated with LR
Table II. Characteristics of patients of this study divided into subgroups with and without local recurrence. Univariate analyses.

\begin{tabular}{|c|c|c|c|c|}
\hline & $\begin{array}{c}\text { Total } \\
\mathrm{n}=606\end{array}$ & $\begin{array}{c}\text { No local } \\
\text { recurrence } \\
n=527 \\
(100 \%)\end{array}$ & $\begin{array}{c}\text { Local } \\
\text { recurrence } \\
\mathrm{n}=79 \\
(100 \%)\end{array}$ & $p$-Value \\
\hline Age (median) & 67 years & 68 years & 66 years & 0.12 \\
\hline Follow-up (median) & 72 months & 79 months & 42 months & $<0.001$ \\
\hline Gender & & & & 0.5 \\
\hline Female & 240 & 206 (39) & $34(43)$ & \\
\hline Male & 366 & $321(61)$ & $45(56)$ & \\
\hline Localization & & & & 0.10 \\
\hline Upper third & 144 & $132(25)$ & $12(15)$ & \\
\hline Middle third & 256 & $222(42)$ & $34(43)$ & \\
\hline Lower third & 206 & $173(33)$ & $33(42)$ & \\
\hline Type of operation & & & & 0.002 \\
\hline $\mathrm{AR}$ & 98 & $92(17)$ & $6(8)$ & \\
\hline LAR & 316 & $282(53)$ & $34(43)$ & \\
\hline APE & 182 & $144(27)$ & $38(48)$ & \\
\hline Hartmann & 11 & $10(2)$ & $1(1)$ & \\
\hline TME & & & & $<0.001$ \\
\hline No & 343 & $284(54)$ & $59(75)$ & \\
\hline Yes & 263 & $243(46)$ & $20(25)$ & \\
\hline T stage & & & & $<0.001$ \\
\hline 1 & 78 & $77(15)$ & $1(1)$ & \\
\hline 2 & 232 & $213(40)$ & $19(24)$ & \\
\hline 3 & 272 & $220(42)$ & $52(66)$ & \\
\hline 4 & 24 & $17(3)$ & $7(9)$ & \\
\hline $\mathrm{N}$ stage & & & & 0.001 \\
\hline 0 & 462 & $411(78)$ & $51(65)$ & \\
\hline 1 & 103 & $88(17)$ & $15(19)$ & \\
\hline 2 & 41 & $28(5)$ & $13(16)$ & \\
\hline Grading* & & & & 0.01 \\
\hline $\mathrm{G} 1 / 2$ & 498 & $444(87)$ & $54(76)$ & \\
\hline $\mathrm{G} 3 / 4$ & 82 & $65(13)$ & $17(24)$ & \\
\hline UICC stage & & & & $<0.001$ \\
\hline I & 266 & $252(48)$ & $14(17)$ & \\
\hline II & 197 & $160(30)$ & 37 (47) & \\
\hline III & 143 & $115(22)$ & $28(35)$ & \\
\hline DM & & & & \\
\hline
\end{tabular}

*Differentiation of the tumor, data missing in 26 cases $(4 \%)$.

(10/263, 3.8\% vs. 39/340, 11.4\%; $p=0.0013)$. The incidence of DM without LR was nearly the same in patients with and without TME (13.6\% vs. $14.7 \%$; Table V). Median time to DM in patients who underwent TME and patients who did not undergo TME was 21 (range $=2.50-85.9$ months) and 21 (range=1.48-85.2 months) months, respectively. The median survival after DM was 16 months without TME and 27 months with TME $(p=0.039)$. In univariate analysis, TME, tumor stage, and LR were significantly associated with DM. Multivariate analyses revealed only three independent risk factors for DM: preceding LR and tumor stage UICC III and II. In contrast, TME was not significantly associated with risk of DM (Table III). 
Table III. Independent risk factors for local recurrence and distant metastases.

\begin{tabular}{|c|c|c|c|c|c|c|c|}
\hline \multirow[t]{2}{*}{ Local recurrence } & \multicolumn{7}{|c|}{ Distant metastases } \\
\hline & HR & $95 \% \mathrm{CI}$ & $p$-Value & & HR & $95 \% \mathrm{CI}$ & $p$-Value \\
\hline TME/PME & & & & TME/PME & & & \\
\hline Grading 3/4 & 2.036 & $1.076-3.86$ & 0.029 & Grading 3/4 & & & \\
\hline APE & 2.065 & $1.195-3.57$ & 0.009 & APE & & & \\
\hline UICC II & 3.115 & $1.486-6.53$ & 0.003 & UICC II & 1.771 & $1.089-2.88$ & 0.021 \\
\hline UICC III & 3.235 & $1.474-7.10$ & 0.003 & UICC III & 3.602 & $2.248-5.77$ & $<0.001$ \\
\hline DM & 3.594 & $1.736-7.44$ & $<0.001$ & LR & 14.780 & $9.315-23.45$ & $<0.001$ \\
\hline Age & & & & & & & \\
\hline
\end{tabular}

TME: Total mesorectal excision; PME: partial mesorectal excision; APE: abdomino-perineal excision; DM: distant metastases; LR: local recurrence.

Incidence of DM in patients with and without LR. DM occurred more often in patients with LR $(49 / 79,62.0 \%)$ than in patients without LR $(86 / 527,16.3 \%$; $p<0.001$; Figure 1$)$. This was independent of gender, TME, tumor localization, type of surgery, grading, and tumor stage (Table VI).

One-third of DM associated with LR occurred before LR $(\mathrm{n}=7,14 \%$, median time to DM 14 months, range 6-31 months) or at the time of LR $(n=11,22 \%)$. In two-thirds $(\mathrm{n}=31,63 \%)$, LR preceded DM (median interval 11.5 months, 2 patients $<0.5$ months, 29 patients, range $=1.6-45.8$ months). This distribution of LR-associated DM was similar in patients who underwent or did not undergo TME (Table V). In 31 patients without DM at diagnosis of LR, the cumulative DM risk for LR increased to $55 \%$ during the first 5 years of follow-up (Figure 2).

The patients with DM before or with LR and patients whose DM occurred after LR were compared to patients with DM but without LR (Table VII). DM occurred more frequently in patients with DM before or with LR than in patients without LR, but the differences were not significant. In contrast, the incidence of DM was significantly higher after diagnosis of LR than in patients without LR in nearly all tumor categories. The differences were most explicit in patients with early cancer. In patients without LR, the frequency of DM increased, with infiltration of the tumor and lymph node involvement. The incidence of DM was high in patients whose DM appeared after LR in all subgroups and did not exhibit increasing incidence with pT and $\mathrm{pN}$ category (Table VII).

The interval from tumor resection to DM differed within the groups: 19 months in patients without LR, 14.7 months in patients with DM before or at LR, and 35.3 months in patients with DM after LR $(p=0.046)$.

Overall survival and cancer-specific survival. The 5- and 10year OS was $67.3 \% \quad(95 \% \mathrm{CI}=63.6-71.3)$ and $47.8 \%$ $(95 \% \mathrm{CI}=43.5-52.4)$ for all patients, $61 \%$ and $43 \%$ for patients who did not undergo TME, and $75 \%$ and $56 \%$ for patients who underwent TME, respectively ( $p=0.001$; Figure 3). In IPTW-weighted Cox regression, the strongest risk factor for OS was DM (HR=9.717, $p<0.001)$, followed by LR $(\mathrm{HR}=7.292, p<0.001)$, UICC stage III (HR1.425, $p=0.033)$, age at surgery $(\mathrm{HR}=1.067, p<0.001)$, and APE $(\mathrm{HR}=1.357, p=0.023)$. TME/PME was not significantly associated with OS. Figure 3 shows the strong correlation between LR, DM, and death when taking into account competing risks.

The 5- and 10-year CSS was 78.5\% (95\% CI=75.1-82.2) and $69.7 \%(95 \% \mathrm{CI}=65.5-74.1)$ for all patients, $73 \%$ and $64 \%$ for patients who did not undergo TME, and $87 \%$ and $79 \%$ for patients who underwent TME, respectively $(p<0.001)$. The independent risk factors for CSS were LR $(\mathrm{HR}=15.062$, $p<0.001)$, DM $(\mathrm{HR}=14.485, p<0.001)$, and UICC stage III $(\mathrm{HR}=1.766, p=0.019)$. TME/PME was a significant protective factor $(\mathrm{HR}=0.475, p=0.001)$.

Adjuvant therapy. The results for 161 patients who underwent adjuvant therapy are given in Table VIII and IX. The LR rates were not significantly different from patients who did not undergo adjuvant therapy, but the rate of DM was higher, probably due to the more advanced tumor stages in these patients. Patients with LR had significantly more DM than patients without LR (Table VIII and IX). In multivariate analyses including these patients, adjuvant treatment was not a significant independent risk factor for LR or DM, OS, or CSS.

\section{Discussion}

Of all DM observed after operative therapy for rectal cancer, approximately one-third were associated with LR. In onethird of cases, DM occurred before or simultaneously with LR. In patients without DM at diagnosis of LR, the incidence of later DM increased to $55 \%$ and significantly exceeded the 


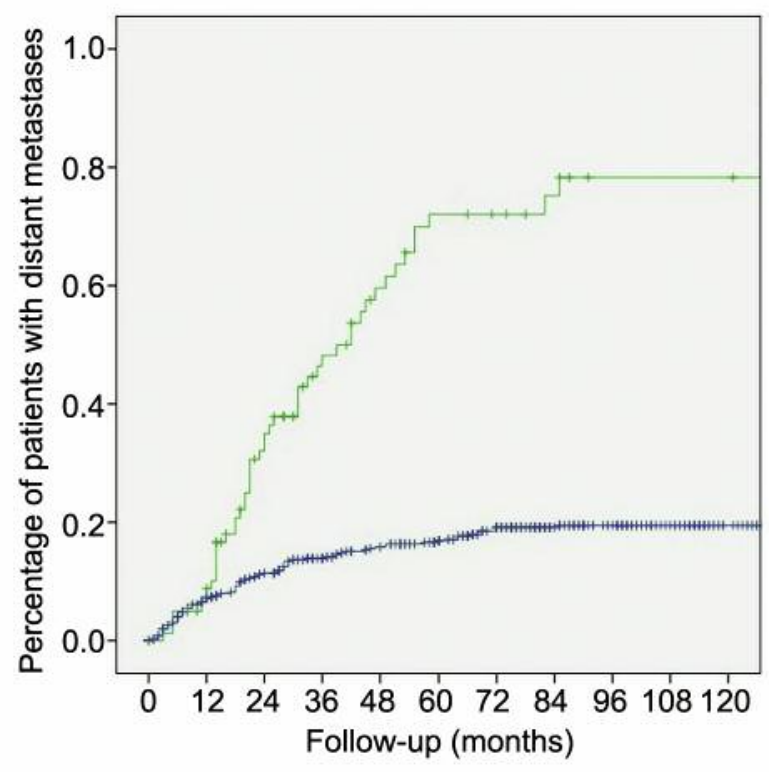

Local recurrence

$\neg$ no LR

$\neg$ LR

+ no LR-censored

+ LR-censored

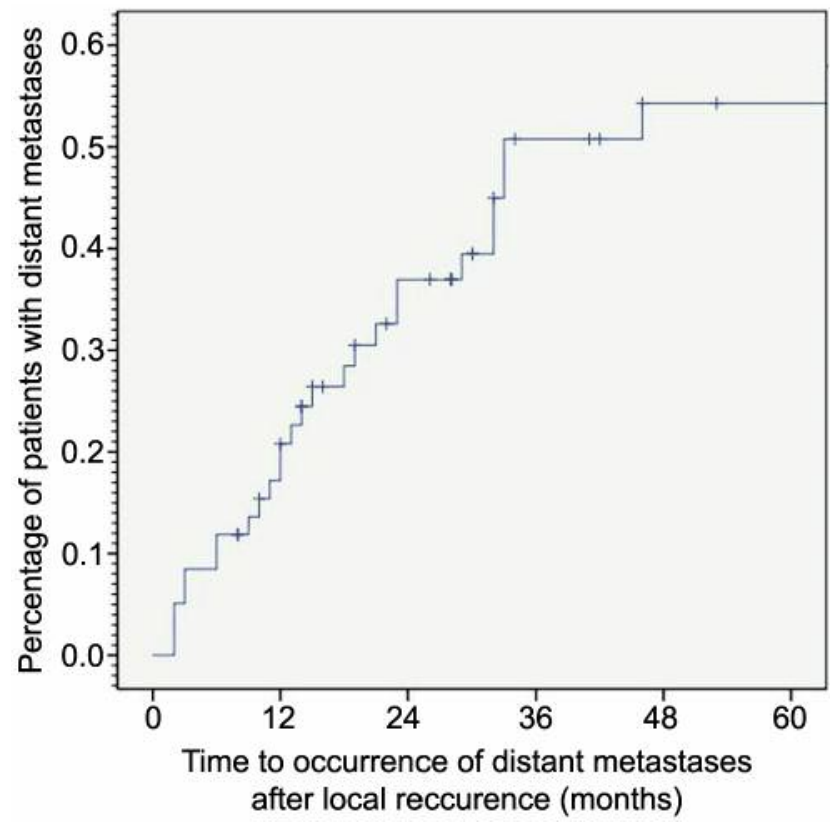

Figure 2. Time to distant metastases (months) following local recurrence in patients without distant metastases before and at the time of local recurrence $(n=31)$.

Figure 1. Distant metastases in patients with $(n=79)$ and without local recurrence $(n=527)$

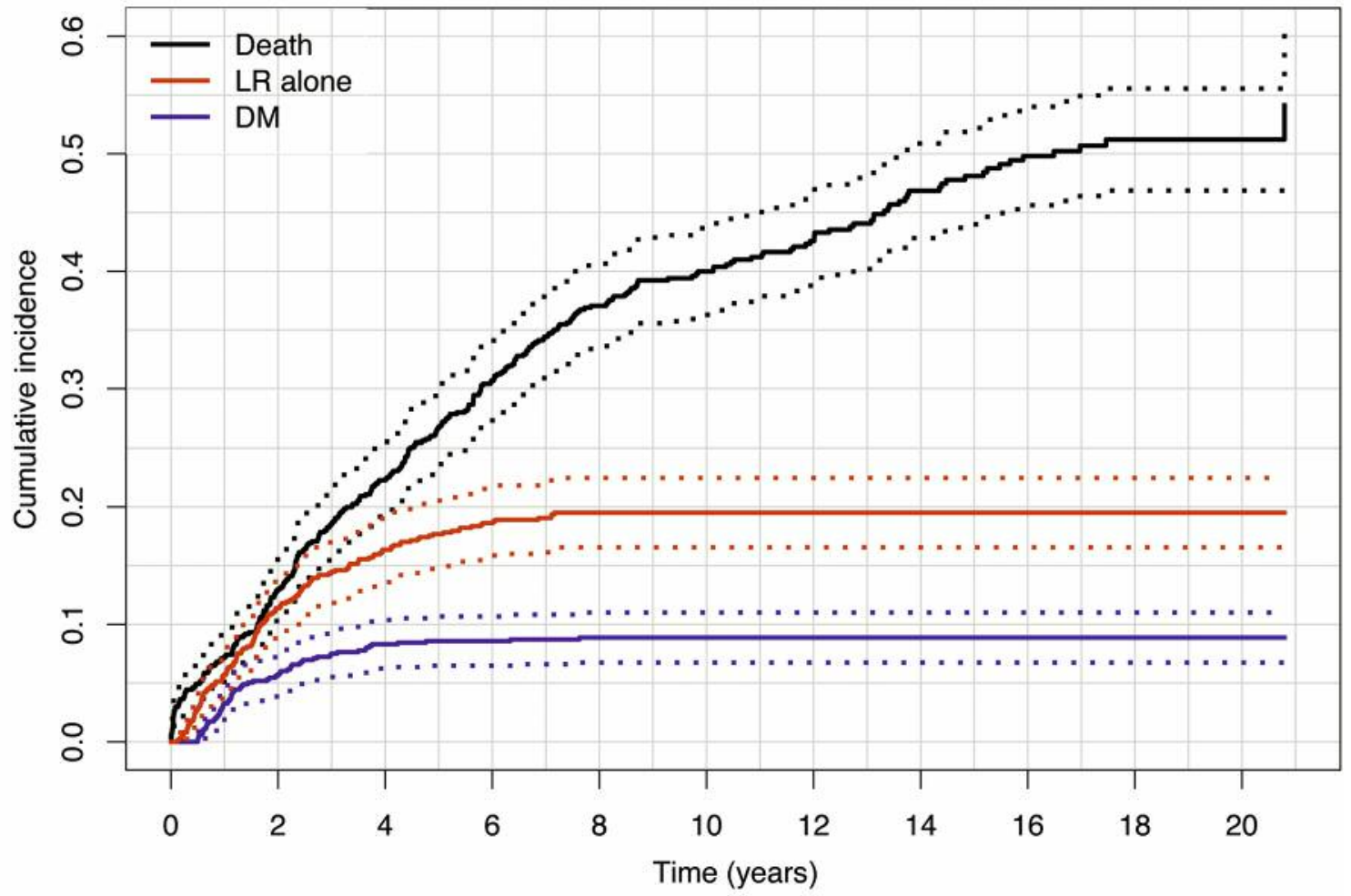

Figure 3. Cumulative incidence of death, local recurrence (LR) without distant metastasis (DM), and DM estimated from a multi-state model taking into account competing risks. 
Table IV. Characteristics of patients of this study divided into subgroups with and without distant metastasis. Univariate analyses.

\begin{tabular}{|c|c|c|c|c|}
\hline & $\begin{array}{c}\text { Total } \\
\mathrm{n}=603^{*}\end{array}$ & $\begin{array}{c}\text { No distant } \\
\text { metastases } \\
\mathrm{n}=468 \\
(100 \%)\end{array}$ & $\begin{array}{c}\text { Distant } \\
\text { metastases* } \\
\mathrm{n}=135 \\
(100 \%)\end{array}$ & $p$-Value \\
\hline Age (median) & 67 years & 67 years & 66 years & 0.481 \\
\hline Follow-up (median) & 72 months & 84 months & 44 months & $<0.001$ \\
\hline Gender & & & & 0.486 \\
\hline Female & 238 & $189(40)$ & $49(36)$ & \\
\hline male & 365 & $279(60)$ & $86(64)$ & \\
\hline Localization & & & & 0.468 \\
\hline Upper third & 143 & $116(25)$ & $27(20)$ & \\
\hline Middle third & 256 & $200(43)$ & $56(42)$ & \\
\hline Lower third & 204 & $152(32)$ & $52(37)$ & \\
\hline Type of operation & & & & 0.205 \\
\hline $\mathrm{AR}$ & 97 & $77(16)$ & $20(16)$ & \\
\hline LAR & 315 & $253(54)$ & $62(45)$ & \\
\hline APE & 180 & $131(28)$ & $49(36)$ & \\
\hline Hartmann & 11 & $7(2)$ & $4(3)$ & \\
\hline TME & & & & 0.049 \\
\hline No & 340 & $251(54)$ & $89(66)$ & \\
\hline Yes & 263 & $217(46)$ & $46(34)$ & \\
\hline T stage & & & & $<0.001$ \\
\hline 1 & 76 & $72(15)$ & $4(3)$ & \\
\hline 2 & 230 & $188(40)$ & $42(31)$ & \\
\hline 3 & 272 & $191(41)$ & $81(60)$ & \\
\hline 4 & 24 & $16(4)$ & $8(6)$ & \\
\hline $\mathrm{N}$ stage & & & & $<0.001$ \\
\hline 0 & 461 & $382(82)$ & $79(59)$ & \\
\hline 1 & 101 & $66(14)$ & $35(26)$ & \\
\hline 2 & 41 & $20(4)$ & $21(15)$ & \\
\hline Grading** & & & & 0.475 \\
\hline $\mathrm{G} 1 / 2$ & 496 & $389(86)$ & $107(84)$ & \\
\hline $\mathrm{G} 3 / 4$ & 81 & $61(14)$ & $20(16)$ & \\
\hline UICC stage & & & & $<0.001$ \\
\hline I & 265 & $234(50)$ & $31(23)$ & \\
\hline II & 197 & $149(32)$ & $48(36)$ & \\
\hline III & 141 & $85(18)$ & $56(41)$ & \\
\hline \multicolumn{5}{|l|}{ Local recurrence } \\
\hline No & 524 & $438(94)$ & $86(64)$ & \\
\hline Yes & 79 & $30(6)$ & $49(36)$ & \\
\hline
\end{tabular}

*Data missing in 3 cases; **differentiation of the tumor, data missing in 26 cases $(4 \%)$.

incidence of DM in patients without LR. Other than tumor stage III and II, earlier LR was the most important independent risk factor for DM.

This study aimed to investigate the link between LR and $\mathrm{DM}$ in patients with rectal cancer in a large sample, with a long-term follow-up. In the group of patients without DM at time of LR, the influence of LR on the later development of DM was demonstrated by an increase in the risk of DM during the first 5 years after diagnosis of LR. The incidence of DM after LR exceeded the incidence of DM in patients without LR in nearly all tumor categories. The influence of increasing
Table V. Incidence of distant metastases in patients with and without total mesorectal excision (TME) depending on time of local recurrence.

\begin{tabular}{lccccc}
\hline \multicolumn{2}{l}{ Patients without TME } & & & & \\
\hline $\mathrm{n}$ & $\begin{array}{c}\text { Total } \\
\text { number } \\
\text { of DM }\end{array}$ & $\begin{array}{c}\text { DM } \\
\text { without } \\
\text { LR }\end{array}$ & $\begin{array}{c}\text { DM } \\
\text { combined } \\
\text { with LR }\end{array}$ & $\begin{array}{c}\text { DM } \\
\text { before } \\
\text { or at LR }\end{array}$ & $\begin{array}{c}\text { DM } \\
\text { after } \\
\text { LR }\end{array}$ \\
\hline 341 & $89 / 340$ & $50 / 89$ & $39 / 89$ & $14 / 39$ & $\begin{array}{c}25 / 39 \\
(26.1 \%)\end{array}$ \\
& $(56 \%)$ & $(44 \%)$ & $(36 \%)$ & $(64 \%)$ \\
\hline Patients with TME & & & & \\
\hline 264 & $46 / 263$ & $36 / 46$ & $10 / 46$ & $4 / 10$ & $6 / 10$ \\
& $(17.5 \%)$ & $(78 \%)$ & $(22 \%)$ & $(40 \%)$ & $(60 \%)$ \\
\hline All & & & & & \\
\hline $603 *$ & $135 / 603$ & $86 / 135$ & $49 / 135$ & $18 / 49$ & $31 / 49$ \\
& $(22.3 \%)$ & $(64 \%)$ & $(36 \%)$ & $(37 \%)$ & $(63 \%)$ \\
\hline
\end{tabular}

*Data missing in three patients. TME: Total mesorectal excision; DM: distant metastases; LR: local recurrence.

tumor infiltration on DM was not more detectable in patients with LR. In particular, patients with LR and low tumor stages developed the highest excess rate of DM, which corresponds to similar observations in patients with LR of other cancers (13). Consistent with this observation, multivariate Cox regression analysis with IPTW revealed only two independent risk factors for DM: earlier LR and tumor stage II and III. These data suggest that, in addition to the primary cancer, LR increases the risk of DM and can be the source of DM.

The interval from tumor resection to DM was longest in patients with DM after LR. In other studies, this was interpreted as evidence of a causal relationship between LR and DM (16), but this interpretation has to be qualified. By group definition alone, patients with DM after LR are guaranteed not to have DM until after LR develops, whereas no such lower bound on elapsed time exists for patients without initial LR.

The percentage of DM caused by LR was probably relatively small. Out of all DM, the percentage of DM combined with LR was $36 \%$; in $63 \%$ of these cases, DM were diagnosed after LR and could have been caused by the LR. DM after LR accounted for 23\% (31/135) of all DM. This proportion depends on the LR rate. The high reduction in absolute LR rates by TME in the present study (9.6\%) explains the significant reduction in DM in these patients. On the other hand, the lower the reduction in LR, the lower the expected effect on DM and OS. This may explain the results of other studies that found no reduction in DM $(7-9,28)$ after reduction of LR. It may also be the reason for LR reduction having no impact on OS in randomized studies $(3,12,29-32)$. 
Table VI. Distant metastasis in patients with and without local recurrence.

\begin{tabular}{|c|c|c|c|c|c|}
\hline & $\begin{array}{c}\text { No LR } \\
n\end{array}$ & $\begin{array}{c}\text { DM without LR* } \\
\text { n (\%) }\end{array}$ & $\begin{array}{c}\mathrm{LR} \\
\mathrm{n}\end{array}$ & $\begin{array}{c}\text { DM with LR } \\
\mathrm{n}(\%)\end{array}$ & $p$-Value $* * *$ \\
\hline Total & 524 & 88 (17) & 81 & $48(59)$ & $<0.001$ \\
\hline \multicolumn{6}{|l|}{ Gender } \\
\hline Female & 204 & $31(15)$ & 36 & $19(53)$ & $<0.001$ \\
\hline Male & 320 & $57(18)$ & 45 & $29(64)$ & $<0.001$ \\
\hline \multicolumn{6}{|l|}{ Localization } \\
\hline Upper third & 132 & $25(19)$ & 12 & $3(25)$ & 0.702 \\
\hline Middle third & 221 & $35(16)$ & 36 & $22(61)$ & $<0.001$ \\
\hline Lower third & 171 & $28(16)$ & 33 & $23(70)$ & $<0.001$ \\
\hline \multicolumn{6}{|c|}{ Type of operation } \\
\hline AR & 90 & $19(21)$ & 7 & $3(43)$ & 0.19 \\
\hline LAR & 282 & $45(16)$ & 35 & $17(49)$ & $<0.001$ \\
\hline APE & 142 & $21(15)$ & 38 & $27(71)$ & $<0.001$ \\
\hline Hartmann & 10 & $3(30)$ & 1 & $1(100)$ & 0.364 \\
\hline \multicolumn{6}{|l|}{ TME } \\
\hline No & 281 & $51(18)$ & 60 & $36(60)$ & $<0.001$ \\
\hline Yes & 243 & 37 (15) & 21 & $12(57)$ & $<0.001$ \\
\hline \multicolumn{6}{|l|}{$\mathrm{T}$ stage } \\
\hline 1 & 76 & $4(5)$ & 1 & 0 & 1.0 \\
\hline 2 & 210 & $29(14)$ & 20 & $15(75)$ & $<0.001$ \\
\hline 3 & 221 & $51(23)$ & 52 & $30(58)$ & $<0.001$ \\
\hline 4 & 17 & $4(24)$ & 8 & $3(38)$ & 0.64 \\
\hline \multicolumn{6}{|l|}{$\mathrm{N}$ stage } \\
\hline 0 & 410 & $52(13)$ & 53 & $27(51)$ & $<0.001$ \\
\hline 1 & 86 & $23(27)$ & 15 & $14(93)$ & $<0.001$ \\
\hline 2 & 28 & $13(46)$ & 13 & $7(54)$ & 0.744 \\
\hline \multicolumn{6}{|l|}{ Grading** } \\
\hline $\mathrm{G} 1 / 2$ & 441 & 75 (17) & 55 & $32(58)$ & $<0.001$ \\
\hline $\mathrm{G} 3 / 4$ & 65 & $10(15)$ & 18 & $11(61)$ & $<0.001$ \\
\hline \multicolumn{6}{|l|}{ UICC stage } \\
\hline I & 249 & $22(9)$ & 15 & $10(66)$ & $<0.001$ \\
\hline II & 161 & $30(19)$ & 38 & $17(45)$ & 0.001 \\
\hline III & 114 & $36(32)$ & 28 & $21(75)$ & $<0.001$ \\
\hline
\end{tabular}

*Data missing in 3 cases; **data missing in 26 cases $(4 \%)$; *** -Values refer to incidence of distant metastasis (DM) in the respective subgroup of patients without and with local recurrence (LR).

One-third of LR-associated DM occurred before or simultaneously with LR. The incidence of DM was not significantly higher than in patients without LR. This suggests that in these patients, the primary cancer as a source of DM outweighs the influence of LR. The strong association between DM and LR in these patients was shown in multivariate analyses where earlier DM was shown to be an independent risk factor for LR. Therefore, in patients with DM after resection of rectal cancer, diagnostic procedures should include a search for LR. Conversely, in the case of LR, the diagnostic evaluation should clarify systemic metastasis.

Even though the introduction of TME in this study was followed by a significant reduction in LR and DM and by an improvement in OS in univariate analyses, these results were not confirmed in multivariate analyses. DM and LR were more important for OS than the performance of TME/PME. This suggests that improvement of OS in patients with rectal cancer cannot be expected with a reduction in LR alone, and the reduction of DM of primary cancer is more important. A promising therapeutic option is systemic preoperative chemotherapy, which is under investigation in patients with rectal and colon cancer $(33,34)$.

The present study has several limitations. First, the study design was a retrospective single-center trial with a long recruitment time. During the observation period, the followup timing and basic diagnostic methods were not changed, with the exception of replacing chest x-ray with CT. However, the quality of the diagnostic methods has steadily improved. Thus, it is possible that more systemic tumor recurrences were detected in later years. The same percentage of DM without LR in patients who underwent and did not undergo TME speaks against such an effect. The results suggest a causal relationship between LR and DM, but cannot provide compelling evidence of this relationship. 
Table VII. Distant metastasis in patients with and without local recurrence.

\begin{tabular}{|c|c|c|c|c|c|c|c|c|c|}
\hline & $\begin{array}{c}\text { No LR } \\
n\end{array}$ & $\begin{array}{c}\text { DM without LR* } \\
\text { n }(\%)\end{array}$ & $\begin{array}{c}\mathrm{LR} \\
\mathrm{n}\end{array}$ & $\begin{array}{c}\text { DM with LR } \\
\text { Total n (\%) }\end{array}$ & $p$-Value $* * *$ & $\begin{array}{c}\text { DM before or at } \mathrm{LR} \\
\mathrm{n}(\mathrm{DM} / \mathrm{LR} \%)\end{array}$ & $p$-Value $* * * *$ & $\begin{array}{c}\text { DM after LR } \\
\mathrm{n}(\mathrm{DM} / \mathrm{LR} \%)\end{array}$ & $p$-Value $* * * * *$ \\
\hline Total & 527 & $86(16)$ & 79 & $49(62)$ & $<0.001$ & $18(23)$ & & $31(39)$ & \\
\hline \multicolumn{10}{|l|}{ Gender } \\
\hline Female & 206 & $29(14)$ & 34 & $20(59)$ & $<0.001$ & $8(24)$ & 0.20 & $12(35)$ & 0.005 \\
\hline Male & 321 & $57(18)$ & 45 & $29(64)$ & $<0.001$ & $10(22)$ & 0.54 & $19(42)$ & 0.001 \\
\hline \multicolumn{10}{|l|}{ Localization } \\
\hline Upper third & 132 & $24(18)$ & 12 & $3(25)$ & 0.699 & 0 & 0.22 & $3(25)$ & 0.698 \\
\hline Middle third & 222 & $34(15)$ & 34 & $22(65)$ & $<0.001$ & $9(26)$ & 0.14 & $13(38)$ & 0.003 \\
\hline Lower third & 173 & $28(16)$ & 33 & $24(73)$ & $<0.001$ & $9(27)$ & 0.14 & $15(45)$ & $<0.007$ \\
\hline \multicolumn{10}{|c|}{ Type of operation } \\
\hline $\mathrm{AR}$ & 92 & $18(20)$ & 6 & $2(33)$ & 0.600 & 0 & 0.59 & $2(33)$ & 0.600 \\
\hline LAR & 281 & $44(16)$ & 34 & $18(53)$ & $<0.001$ & $6(18)$ & 0.80 & $12(35)$ & 0.008 \\
\hline APE & 144 & $21(15)$ & 38 & $28(74)$ & $<0.001$ & $11(29)$ & 0.06 & 17 (44) & $<0.001$ \\
\hline Hartmann & 10 & $3(30)$ & 1 & 1 & 0.363 & 1 & 0.36 & 0 & 1.0 \\
\hline \multicolumn{10}{|l|}{ TME } \\
\hline No & 284 & $50(18)$ & 59 & $39(66)$ & $<0.001$ & $14(24)$ & 0.28 & $25(42)$ & 0.424 \\
\hline Yes & 243 & $36(15)$ & 20 & $10(50)$ & $<0.001$ & $4(20)$ & 0.52 & $6(30)$ & 0.300 \\
\hline \multicolumn{10}{|l|}{$\mathrm{T}$ stage } \\
\hline 1 & 77 & $4(5)$ & 1 & 0 & 1.0 & 0 & 1.0 & 0 & 1.0 \\
\hline 2 & 213 & $28(13)$ & 19 & $14(74)$ & $<0.001$ & $4(21)$ & 0.31 & $10(53)$ & $<0.001$ \\
\hline 3 & 220 & $50(23)$ & 52 & $31(58)$ & $<0.001$ & $11(21)$ & 1.0 & $20(38)$ & 0.023 \\
\hline 4 & 17 & $4(24)$ & 7 & $4(38)$ & 0.167 & $3(43)$ & 0.37 & 1 & 1.0 \\
\hline \multicolumn{10}{|l|}{$\mathrm{N}$ stage } \\
\hline 0 & 411 & $51(12)$ & 51 & $28(54)$ & $<0.001$ & $9(18)$ & 0.28 & $19(37)$ & $<0.001$ \\
\hline 1 & 88 & $22(26)$ & 15 & $13(87)$ & $<0.001$ & $6(40)$ & 0.35 & $7(47)$ & 0.123 \\
\hline 2 & 28 & $13(46)$ & 13 & $8(62)$ & 0.505 & $3(23)$ & 0.19 & $5(38)$ & 0.741 \\
\hline \multicolumn{10}{|l|}{ Grading** } \\
\hline $\mathrm{G} 1 / 2$ & 444 & $74(17)$ & 54 & $33(61)$ & $<0.001$ & $8(15)$ & 0.85 & $25(46)$ & $<0.001$ \\
\hline $\mathrm{G} 3 / 4$ & 65 & $9(14)$ & 17 & $11(65)$ & $<0.001$ & $6(35)$ & 0.07 & $5(29)$ & 0.157 \\
\hline \multicolumn{10}{|l|}{ UICC stage } \\
\hline I & 252 & $22(9)$ & 14 & $9(64)$ & $<0.001$ & $3(21)$ & 0.13 & $6(43)$ & 0.001 \\
\hline II & 160 & $29(18)$ & 37 & $19(51)$ & $<0.001$ & $6(16)$ & 1.0 & $13(35)$ & 0.043 \\
\hline III & 115 & $35(30)$ & 28 & $21(75)$ & $<0.001$ & $9(32)$ & 1.0 & $12(43)$ & 0.266 \\
\hline \multicolumn{10}{|c|}{ Interval (months) } \\
\hline median & & 19.0 & & & & 14.7 & & 35.3 & \\
\hline
\end{tabular}

*Data missing in 3 cases; **data missing in 26 cases (4\%); ***values refer to incidence of DM in respective subgroup of patients without and with $\mathrm{LR}$; ****p-Values refer to incidence of DM in respective subgroup of patients without LR and patients with DM before or at LR; $* * * * * p$-Values refer to incidence of DM in respective subgroup of patients without LR and patients with DM after LR.

Table VIII. Local recurrence and distant metastases in patients after surgery and adjuvant therapy.

\begin{tabular}{lcccc}
\hline Adjuvant treatment & Total & Local recurrence & $p$-Value & Distant metastasis \\
\hline & & & 0.405 & $30(39)$ \\
Adjuvant R(C)T & 79 & $16(20)$ & & $18(45)$ \\
Adjuvant CT & 41 & $5(12)$ & $3(7)$ \\
Neoadjuvant RCT & 41 & $6(15)$ & & $<.001$ \\
\hline
\end{tabular}

RCT: Radiochemotherapy; CT: chemotherapy.

This would require a method for detecting systemic micrometastases at the time of diagnosis of primary cancer. In addition, in the beginning of TME surgery, quality was not routinely determined, so consistent data are not available on the influence of TME quality on LR and OS. The aim of this study was not to evaluate TME or follow-up after surgery, but to better characterize the relationship between LR, DM, and OS. 
Table IX. Distant metastasis in patients without and with LR after surgery and adjuvant therapy.

\begin{tabular}{lccccc}
\hline Adjuvant treatment & No LR & DM without LR & LR & DM with LR & $p$-Value** \\
\hline Adjuvant R(C)T & 63 & $19(30)$ & 16 & $11(69)$ & 0.009 \\
Adjuvant CT & 36 & $13(36)$ & 5 & $5(100)$ & 0.013 \\
Neoadjuvant RCT & 35 & $2(7)$ & 6 & $1(17)$ & 0.386 \\
\hline
\end{tabular}

LR: Local recurrence; DM: distant metastasis; RCT: radiochemotherapy; CT: chemotherapy. ${ }^{* *} p$-Values refer to the incidence of distant metastasis in the respective subgroup of patients without LR.

In conclusion, our results suggest two mechanisms responsible for the development of DM in patients with rectal cancer. In addition to systemic micrometastases originating from the primary cancer and existing at the time of diagnosis, residual tumor or implanted tumor cells at the site of resection are a possible source of DM. The percentage of DM caused by LR seems to be relatively low, explaining the missing effect of reduced LR on prognosis in some studies. On the other hand, these mechanisms may explain the high risk of DM and unfavorable prognosis of patients with LR of rectal cancer $(35,36)$.

\section{Conflicts of Interest}

The Authors have no conflicts of interest to disclose. The Authors confirm that they were not supported by any grants, equipment, or organizations.

\section{Authors' Contributions}

T.J. and A. H. participated in the design of the study, U.G., T.T. and A. H. provided clinical data, A.L., M.B. and D.W. performed statistical analyses and interpretation of data, A.L. and D.W. generated figures, T.J. and D.W. drafted the manuscript, which was critically revised by all Authors.

\section{References}

1 Peeters KCMJ, Marijnen CAM, Nagtegaal ID, Kranenbarg EK, Putter H, Wiggers T, Rutten H, Pahlman L, Glimelius B, Leer JW and van de Velde CJ; Dutch Colorectal Cancer Group: The TME trial after a median follow-up of 6 years. Increased local control but no survival benefit in irradiated patients with resectable rectal carcinoma. Ann Surg 246: 693-670, 2007. PMID: 17968156. DOI: 10.1097/01.sla.0000257358.56863.ce

2 Bujko K, Nowacki MP, Nasierowska-Guttmejer A, Michalski W, Bebenek M and Kryj M: Long-term results of a randomized trial comparing preoperative short-course radiotherapy with preoperative conventionally fractionated chemoradiation for rectal cancer. Br J Surg 93: 1215-1223, 2006. PMID: 16983741. DOI: $10.1002 /$ bjs.5506

3 Sauer R, Liersch T, Merkel S, Fietkau R, Hohenberger W, Hess C, Becker H, Raab HR, Villanueva MT, Witzigmann H, Wittekind C, Beissbarth T and Rödel C: Preoperative chemoradiotherapy for locally advanced rectal cancer: results of the German CAO/ARO/AIO-94 randomized phase III trial after a median follow up of 11 years. J Clin Oncol 30: 1926-1933, 2012. PMID: 22529255. DOI: $10.1200 / J C O .2011 .40 .1836$

4 MacFarlane JK, Ryall RD and Heald RJ: Mesorectal excision for rectal cancer. Lancet 341: 457-460, 1993. PMID: 8094488.

5 Havenga K, Enker WE, Norstein J, Moriya Y, Heald RJ, van Houwelingen $\mathrm{HC}$ and van de Velde CJ: Improved survival and local control after total mesorectal excision or D3 lymphadenectomy in the treatment of primary rectal cancer: an international analysis of 1411 patients. Eur J Surg Oncol 25: 368374, 1999. PMID: 10419706.

6 Bernstein TE, Endreseth BH, Romundstad P and Wibe A; Norwegian Colorectal Cancer Registry: Improved local control of rectal cancer reduces distant metastases. Colorectal Dis 14: e668-678, 2012. PMID: 22646752. DOI: 10.1111/j.1463-1318. 2012.03089.x

7 Köckerling F, Reymond MA, Altendorf-Hofmann A, Dworak O and Hohenberger W: Influence of surgery on metachronous distant metastases and survival in rectal cancer. J Clin Oncol 16: 324-329, 1998. PMID: 9440760.

8 Martling AL, Holm T, Rutqvist LE, Moran BJ, Heald RJ and Cedemark B: Effect of a surgical training programme on outcome of rectal cancer in the countries of Stockholm. Lancet 356: 93-96, 2000. PMID: 10963244.

9 Kapiteijn E, Putter $\mathrm{H}$ and van de Velde CJ; Cooperative investigators of the Dutch ColoRectal Cancer Group: Impact of the introduction and training of total mesorectal excision on recurrence and survival in rectal cancer in The Netherlands. $\mathrm{Br}$ J Surg 89: 1142-1149, 2002. PMID: 12190680.

10 Rich T, Gunderson LL, Lew R, Galdibini JJ, Cohen AM and Donaldson G: Patterns of recurrence of rectal cancer after potentially curative surgery. Cancer 52: 1317-1329, 1983. PMID: 6192900.

11 Stipa F, Giaccaglia V and Burza A: Management and outcome of local recurrence following transanal endoscopic microsurgery for rectal cancer. Dis Colon Rectum 55: 262-269, 2012. PMID: 22469792. DOI: 10.1097/DCR.0b013e318241ef22

12 Holm $\mathrm{T}$, Rutqvist LE, Johansson $\mathrm{H}$ and Cedermark B: Abdominoperineal resection and anterior resection in the treatment of rectal cancer: results in relation to adjuvant preoperative radiotherapy. Br J Surg 82: 1213-1216, 1995. PMID: 7551999.

13 Leibel SA, Scott CB, Mohiuddin M, Marcial VA, Coia LR, Davis LW and Fuks Z: The effect of local-regional control on distant metastatic dissemination in carcinoma of the head and neck: results of an analysis from the RTOG Head and Neck 
Database. Int J Radiat Oncol Biol Phys 21: 549-556, 1991. PMID: 1869453.

14 Fuks Z, Leibel SA, Wallner KE, Begg CB, Fair WR, Anderson LL, Hilaris BS and Whitmore WF: The effect of local control on metastatic dissemination in carcinoma of the prostate: long-term results in patients treated with 125 I Implantation. Int J Radiat Oncol Biol Phys 21: 537-547, 1991. PMID: 1869452.

15 Koscielny S and Tubiana M: The link between local recurrence and distant metastases in human breast cancer. Int J Radiat Oncol Biol Phys 43: 11-24, 1999. PMID: 9989510.

16 Vicini FA, Kestin L, Huang R and Martinez A: Does local recurrence affect the rate of distant metastases and survival in patients with early-stage breast carcinoma treated with breastconserving therapy? Cancer 97: 910-919, 2003. PMID: 12569590.

17 Rothman K, Greenland S and Lash T: Modern Epidemiology 3rd ed, Lippincott Williams \& Wilkins, pp. 106-107, 2008.

18 UICC, Sobin LH and Wittekind CH (eds.): TNM classification of malignant tumors, 6th ed. New York, Wiley-Liss, 2002.

19 Heald RJ, Husband EM and Ryall RD: The mesorectum in rectal surgery-the clue to pelvic recurrence? Br J Surg 69: 613-616, 1982. PMID: 6751457.

$20 \mathrm{Kim}$ CH, Lee SY, Kim HR and Kim YJ: Pathological stage following preoperative chemoradiotherapy underestimates the risk developing distant metastases in rectal cancer: A comparison to staging without preoperative cheomoradiotherapy. J Surg Oncol 113: 692-699. 2016. PMID: 26914147. DOI: 10.1002/jso.24207

21 Cole SR and Hernán M: Constructing inverse probability weights for marginal structural models. Am J Epidemiol 168: 656-664, 2008. PMID: 18682488. DOI: 10.1093/aje/kwn164

22 Funk MJ, Westreich D, Wiesen C, Stürmer T, Brookhart MA and Davidian M: Robust estimation of causal effects. Am J Epidemiol 173: 761-767, 2011. PMID: 21385832. DOI:10.1093/aje/kwq439

23 Austin PC: Variance estimation when using inverse probability of treatment weighting (IPTW) with survival analysis. Stat Med 35: 5642-5655, 2016. PMID: 2754901. DOI: 10.1002/sim.7084

24 Beyersmann J, Allignol A and Schumacher M: Competing Risks and Multistate Models with R. Springer, New York, 2012.

25 R Core Team. R: A Language and Environment for Statistical Computing. Vienna, Austria: R Foundation for Statistical Computing, 2017.

26 Therneau TM and Grambsch PM: Modeling survival data: extending the Cox model. Springer, New York, 2000.

27 Allignol A, Schumacher $M$ and Beyersmann J: Empirical Transition Matrix of Multi-State Models: The etm Package. J Statistical Software 38: 1-15, 2011. DOI: 10.18637/jss.v038.i04

28 Alberda WJ, Verhoef C, Nuyttens JJ, Rothbarth J, van Meerten E, de Wilt JH and Burger JW: Outcome in patients with resectable locally recurrent rectal cancer after total mesorectal excision with and without previous neoadjuvant radiotherapy for the primary rectal tumor. Ann Surg Oncol 21: 520-526, 2014. PMID: 24121879. DOI: 10.1245/s10434-013-3306-x
29 Nesbakken A, Nygaard K, Westerheim O, Mala T and Lunde OC: Local recurrence after mesorectal excision for rectal cancer. Eur J Surg Oncol 28: 126-134, 2002. PMID: 11884047.

30 Gérard A, Buyse M, Nordlinger B, Loygue J, Pène F, Kempf P, Bosset JF, Gignoux M, Arnaud JP and Desaive C: Preoperative radiotherapy as adjuvant treatment in rectal cancer. Final results of a randomized study of the European Organisation for Research and Treatment of Cancer (EORTC). Ann Surg 208: 606-614, 1988. PMID: 3056288. DOI: 10.1097/00000658198811000-00011

31 Sebag-Montefiore D, Stephens RJ, Steele R, Monson J, Grieve R, Khanna S, Quirke P, Couture J, de Metz C, Myint AS, Bessell E, Griffiths G, Thompson LC and Parmar M: Preoperative radiotherapy versus selective postoperative chemoradiotherapy in patients with rectal cancer (MRC CR 07 and NCIC CTG C016): A multicentre, randomised trial. Lancet 373: 811-820, 2009. PMID: 19269519. DOI: 10.1016/S0140-6736(09)60484-0

32 van Gijn W, Marijnen CA, Nagtegaal ID, Kranenbarg EM, Putter H, Wiggers T, Rutten HJ, Påhlman L, Glimelius B, van de Velde CJ; Dutch Colorectal Cancer Group: Preoperative radiotherapy combined with total mesorectal excision for resectable rectal cancer: 12-year follow-up of the multicentre, randomized controlled TME trial. Lancet Oncol 12: 575-582, 2011. PMID: 21596621. DOI: 10.1016/S1470-2045(11)70097-3

33 Foxtrot Collaborative Group: Feasibility of preoperative chemotherapy for locally advanced, operable colon cancer: the pilot phase of a randomised controlled trial. Lancet Oncol 13: 1152-1160, 2012. PMID: 23017669. DOI: 10.1016/S14702045(12)70348-0

34 Schrag D, Weiser MR, Goodman KA, Gonen M, Hollywood E, Cercek A, Reidy-Lagunes DL, Gollub MJ, Shia J, Guillem JG, Temple LK, Paty PB and Saltz LB: Neoadjuvant chemotherapy without routine use of radiation therapy for patients with locally advanced rectal cancer: a pilot trial. J Clin Oncol 32: 513-518, 2014. PMID: 24419115. DOI: 10.1200/JCO.2013.51.7904

35 van den Brink M, Stiggelbout AM, van den Hout WB, Kievit J, Klein Kranenbarg E, Marijnen CA, Nagtegaal ID, Rutten HJ, Wiggers $\mathrm{T}$ and van de Velde CJ: Clinical nature and prognosis of locally recurrent rectal cancer after total mesorectal excision with or without preoperative radiotherapy. J Clin Oncol 22: 3958-3964, 2004. PMID: 15459218.

36 Bikhchandani J, Ong GK, Dozois EJ and Mathis KL: Outcomes of salvage surgery for cure in patients with locally recurrent disease after local excision of rectal cancer. Dis Colon Rectum 58: 283-287, 2015. PMID: 25664705. DOI: 10.1097/DCR. 0000000000000283 